\title{
Energy Balance Analysis and Turbulence Profile of a Darrieus-type Vertical Axis Wind Turbine
}

\author{
Yin Mun H'ng, ${ }^{1}$ Yusri Yusup ${ }^{2 *}$ and Sheikh Ahmad Zaki ${ }^{1}$ \\ ${ }^{1}$ Malaysia-Japan International Institute of Technology (MJIT), \\ Universiti Teknologi Malaysia, 54100 Jalan Semarak, Kuala Lumpur, Malaysia \\ ${ }^{2}$ Environmental Technology, School of Industrial Technology, \\ Universiti Sains Malaysia, 11800 USM Pulau Pinang, Malaysia \\ ${ }^{*}$ Corresponding author: yusriy@usm.my
}

Published online: 25 April 2019

To cite this article: H'ng, Y. M., Yusup, Y. \& Ahmad Zaki, S. (2019). Energy balance analysis and turbulence profile of a Darrieus-type vertical axis wind turbine. J. Phys. Sci., 30(1), 47-70, https://doi.org/10.21315/jps2019.30.1.5

To link to this article: https://doi.org/10.21315/jps2019.30.1.5

\begin{abstract}
Vertical axis wind turbines (VAWTs) extract energy through reduction of the kinetic and turbulent kinetic energies, and the vertical momentum flux. Detailed turbulence profiling and energy balance analysis were attempted through direct turbulence quantification using the Eddy Covariance method. A high-frequency sonic anemometer was employed to measure flow and turbulence upwind and downwind of a Darrieus-type $V A W T$ at different positions that cover the entire windswept area. The data was processed and analysed using a custom Matlab script. Energy balance analysis showed that there was a significant drop in kinetic energy before and after the VAWT (72\% to 42\%) but a small increase in turbulent kinetic energy (28\% to 31\%). The results also showed that the rotational direction of VAWT contributed to a higher value of longitudinal turbulence at the windward edge of the VAWT. The VAWT affected the flow field upwind by generating reverse flows. The largest vertical momentum flux transfer occurred downwind of the windward side of the VAWT. Spectral analysis shows that the VAWT produced smaller but faster momentum flux vortices due to the rotating rotors in the $1 \mathrm{~Hz}$ to $5 \mathrm{~Hz}$ range. This data and results have important applications to accurately model complex flows around VAWTS.
\end{abstract}

Keywords: Energy budget, Eddy Covariance, turbulent kinetic energy, kinetic energy, VAWT 


\section{INTRODUCTION}

Wind energy is a viable renewable energy alternative that has the potential to assist communities and nations to achieve energy sustainability goals. However, further work is needed to increase its energy collection efficiency and versatility. There are two types of wind turbines: the vertical axis wind turbine (VAWT) and the horizontal axis wind turbine (HAWT). Although VAWTs are thought to be not as efficient as HAWTs, $10 \%$ versus $50 \%$ efficiency, VAWTs have the ability to receive the wind from all horizontal and vertical directions that are common in urban areas. ${ }^{1}$ Because of this, the VAWT will be able to function well under turbulent flow conditions. ${ }^{2}$ Nevertheless, the efficiency of VAWTs has become higher compared with HAWTs in recent years. With more modification and improvement, VAWTs could achieve a maximum power coefficient of $40 \%$ and torque coefficient of $43 \%$, which are comparable to the HAWT. ${ }^{3}$ A study proposed the use of Maglev to increase the efficiency of the VAWT while another study focused on the design of the generator (e.g., the permanent magnet synchronous generator) to increase power generation at low wind speed conditions. ${ }^{4-6}$ The use of magnetic gears shows promise as they are found to greatly enhance generator performance even at low wind speed conditions. ${ }^{7}$ Aside from generating power, the feasibility to store power using batteries on an off-grid super-capacitator was also reported. ${ }^{8}$ Some studies have reported that, when installed on building rooftops, small-scale VAWTs (rate $1000 \mathrm{~W}$ or less) are practical and sustainable energy providers because it can be positioned close to the end user. ${ }^{1,9-11}$ A study found that by placing many VAWTs in an array, wind energy extraction per unit area could be significantly increased, making it even more attractive for urban locations with surface area constraints. ${ }^{12}$ This finding was also found to be correct in a study by Kinzel et al., who showed that the pairing of VAWTs could reduce the size of wind farms. However, flow conditions on urban surfaces are slow and dynamic and predominantly "unstable" due to buoyancy effects caused by the surface material of urban surfaces (e.g., concrete, asphalt, etc.). ${ }^{13,14}$ Convective turbulence might damage the VAWTs or degrade their performance. ${ }^{15}$ Thus, to further improve their performance and longevity in urban settings, it is vital to have an in-depth understanding of the turbulence profile of the VAWT. ${ }^{14}$

How do turbulence fluxes behave in the wake of a VAWT in low wind speed but turbulent conditions? To answer this question, direct measurements of VAWT turbulence using the Eddy Covariance (EC) method in a controlled indoor laboratory environment is conducted. The EC method is a direct technique to measure turbulent fluxes using a fast-response anemometer. The EC method is commonly used to quantify carbon dioxide, water vapour and momentum fluxes in micrometeorological studies. ${ }^{16}$ Researchers successfully employed this method 
in a VAWT turbulence study on a building rooftop. ${ }^{14,17}$ Although there have been studies that report the association between micrometeorological parameters (e.g., atmospheric stability, momentum transfer, convective motion, etc.) and wind turbines, the literature lacks reports of direct measurements of wind turbine turbulence. However, there is a study that described the effect of atmospheric stability on HAWT performance and another pilot study that quantified the turbulent fluxes of a VAWT. ${ }^{18,19}$ Yet, the former turbulence research focused on the HAWTs while other studies used simulation software. ${ }^{15,20}$ One study of a Darrieustype VAWT on a rooftop used OpenFOAM, a numerical computational fluid dynamic software package, to calculate the flow fields around the turbine. ${ }^{1}$ But, the results of these numerical models would need to be validated by experimental measurements. Hence, this study provides important empirical data to improve the accuracy of these models.

The limitation of this work is that only a specific range of wind speed (i.e., 3-4 $\mathrm{m} \mathrm{s}^{-1}$ ) can be considered due to the nature of the experimental setup (detailed in Section 2). This speed range corresponded to lower VAWT efficiencies, and thus, the results reported would only represent the performance of the VAWT under relatively low wind speed condition. However, this situation is typical for urban or high surface roughness surfaces of which VAWTs are commonly installed and hence, would be of great value for many, if not all, VAWT applications. Another limitation is that the results could be only applicable to a particular VAWT design. Nonetheless, since the study is about turbulence, the aspect of the design is not the focus of this work.

This paper begins by analysing the upwind and downwind flow and turbulence characteristics of a generic Darrieus-type (lift-type) VAWT to determine plausibility and coherence with the literature. Next, it examines the partitioning of kinetic and turbulent kinetic energies using an energy balance model. Finally, it discusses the magnitude and importance of momentum flux in the overall energy budget and the spectral characteristics of the momentum flux component.

\section{EXPERIMENTAL}

\subsection{Experimental Setup}

This experiment was conducted in a controlled indoor laboratory with dimensions of $3.0 \mathrm{~m} \times 5.5 \mathrm{~m}$ with minimal obstruction of flow. Three 26 " industrial standing fans with blade lengths of $0.35 \mathrm{~m}$ were arranged in a row and at different heights from the ground, shown in Figure 1(a), to generate the flow field. Figure 1 illustrates: (a) upwind position without VAWT; (b) downwind position without 
VAWT; (c) upwind position with VAWT; (d) downwind position with VAWT; (e) grid shelf covered the entire flow swept area of the flow field with 30 data measurement positions referred to as "cells" (A1, A2, A3, A4, A5, A6, B1,... E6, where A, B, C, etc., are referred to as "columns" and 1, 2, 3, etc., are referred to as "rows"); and (f) schematic diagram of the Darrieus-type VAWT with chord length of $1.20 \mathrm{~m}$. This fan-generated flow field configuration was recommended by Wahab and Tong so that a uniform flow field over the swept area can be produced. ${ }^{21}$ However, it is important to note that the flow could be "cyclone"-shaped due to the vortices generated by the fans. The available flow speed settings of the fans were "low" $\left(3.2 \mathrm{~m} \mathrm{~s}^{-1}\right)$ and "high" $\left(4.0 \mathrm{~m} \mathrm{~s}^{-1}\right)$. At the low-speed setting, Reynolds number, $N_{R e}$ was $1.31 \times 10^{8}$ while at the high-speed setting, $N_{R e}$ was $1.63 \times 10^{8}$, and thus, the difference in turbulent flow conditions between the two-speed settings were marginal. In the centre of the swept area, the average mean flow velocity at the high-speed setting was $4.0 \mathrm{~m} \mathrm{~s}^{-1}$. Based on an initial assessment of the data, only the highest flow speed setting of the fans was used for further analysis. The turbulences magnitudes were similar throughout the VAWT flow swept area for both the low and high-speed settings. The uncertainties and errors associated with the different placement of the VAWT (or industrial fans) have been reported in H'ng et al. ${ }^{19}$

The three velocity wind components were measured upwind and downwind (hereafter referred to as "in the wake") of the VAWT. The VAWT was a $300 \mathrm{~W}$ three-bladed Darrieus-type (or lift-type) VAWT (model number iW301, iWind Energy, Taiwan) with a total swept area of $1.44 \mathrm{~m}^{2}$ and blade edge distance to the VAWT centre (or radius) of $1.20 \mathrm{~m}$, shown in Figure 1(f). The specifications of the cut-in wind speed and the survival wind speed provided by the manufacturer are $2.5 \mathrm{~m} \mathrm{~s}^{-1}$ and $30 \mathrm{~m} \mathrm{~s}^{-1}$, respectively. The VAWT rotated within the range of 75-79 rotation per minute (RPM), approximately $1.28 \mathrm{~Hz}$, at the low-speed setting; while at high-speed setting, the VAWT rotated in the range of 101-105 RPM, about 1.72 $\mathrm{Hz}$. The estimated tip speed ratio (TSR), $\lambda$, is in the range between 1.51 and 1.62 which is found to be well below the optimal $\lambda$ for three-bladed rotors (4.19). ${ }^{22} \mathrm{~A}$ sonic anemometer (model number 81000, RM Young, United States) was used to measure the three-component flow velocities generated from the industrial standing fans and VAWT as shown in Figure 1(b) placed $1.35 \mathrm{~m}$ upwind and downwind of the centre of the VAWT. This distance ensures that the flow measurements were representative of flow fields directly around the VAWT. The sonic anemometer was positioned per a fabricated guiding grid shelf, as in Figure 1(e) to measure the flow velocities at specific locations of the swept area, where each label indicates the data measurement positions (hereafter referred to as "cells"). Column A is the leeward side while column $\mathrm{E}$ is the windward side; row 1 was the top and row 6 was the bottom of the measurement domain. The raw time series data were directly 
logged to a personal computer via an RS232 cable using the software Hyperterm (Microsoft, United States) as the interface. For every sampling run, $u, v$ and $w$ data were measured at $10 \mathrm{~Hz}$ for the duration of $60 \mathrm{~min}$ with a total of 36000 data points. A total of 240 sampling runs were performed to obtain a complete profile of the flow upwind and downwind of the VAWT as well as for runs with and without the VAWT. The flow field generated was steady for the entire duration of the experiment.

(a)

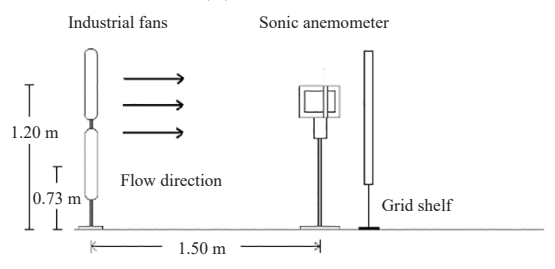

(c)

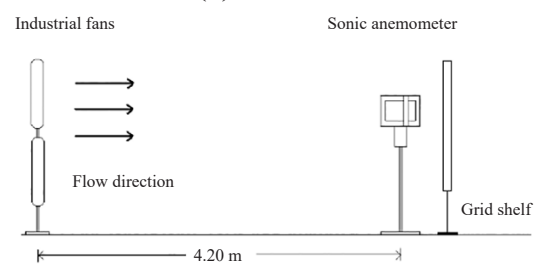

(e)

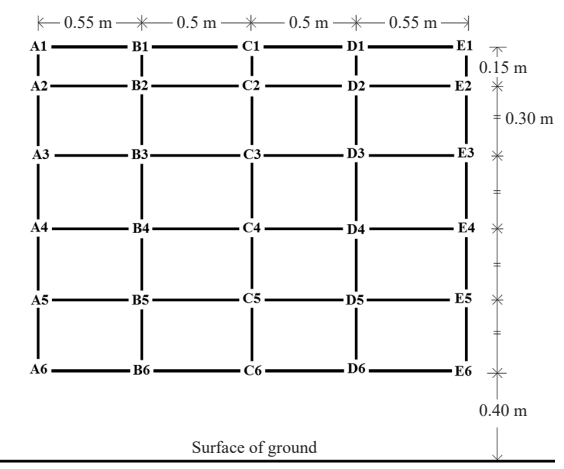

(b)

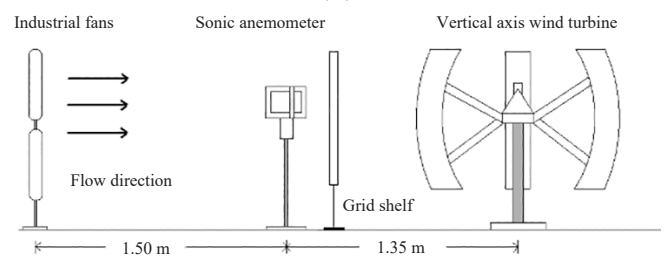

(d)

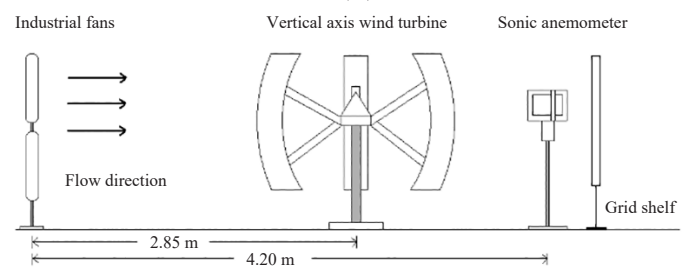

(f)
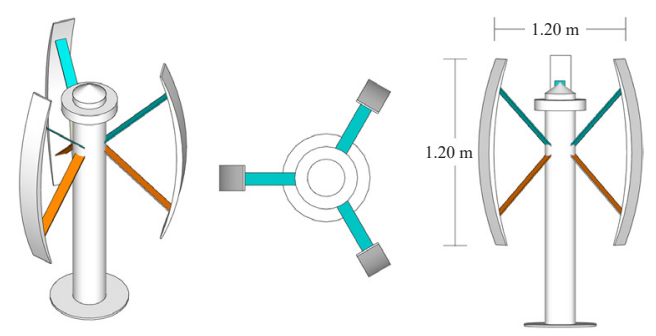

$\underline{\text { Top view }}$

Figure 1: Upwind and downwind positions of the sonic anemometer with the fabricated grid shelf as positioning reference relative to the VAWT and the three 26" industrial standing fans. 


\subsection{Data Quality Control and Processing}

Data quality control checks were performed based on recommendations by Vickers and Mahrt. ${ }^{23}$ The raw $10 \mathrm{~Hz}$ time series data were processed and analysed using a custom Matlab script (version R2012a, MathWorks, United States) as used in our previous urban turbulence studies. ${ }^{24,25}$

Spike removal, Haar transform, skewness and kurtosis tests were conducted before calculating the 60 -min block-averaged flow speed, turbulence and flux parameters. Data spikes, defined as velocity measurement exceeding 3.5 standard deviation of the block-averaged mean, were removed. The "double rotation" method was then applied to every averaging block to align the velocities to orthogonal axes: the $x, y$, and $z$-axes, which could minimise the effect of the cyclone-shaped vortices produced by the industrial fans. ${ }^{26}$ Haar transform was then employed to flag raw data discontinuities; skewness (ideal skewness $=0 ;-2<$ skewness $<2$ ) and kurtosis (ideal kurtosis $=3 ; 1<$ kurtosis $<8$ ) beyond the acceptable range were "hard"flagged and subsequently omitted.

The calculated block-averaged flow and turbulence parameters were then subjected to the random flux error and stationarity tests. ${ }^{23}$ Random flux error $(R F E)$ is a test to determine the steadiness of 5-min flux averaged-blocks (based on kinematic heat flux) within the overall 60-min block-averaged window. If $R F E>0.25$, the block is then "soft"-flagged but can still be considered in further analysis. However, averaged $R F E$ results were $<0.05$ and thus, none of the data was soft-flagged due to this test. The data was then examined using the stationarity test $(R N)$, which could identify the non-stationarity of fluxes over the block-averaged window. Like $R F E$, the criterion was that $R N$ must be less than 0.25 to ascertain that flow and turbulence parameters calculated were statistically stationary. $R N$ was also found to be always less than 0.05 , and thus no fluxes were soft-flagged due to this test. Overall, although some data points were removed due to spikes (overall $<0.5 \%$ of each block), time series data or flow and turbulence flow parameters calculated were never removed due to failing the Haar transform, kurtosis, skewness, RFE or $R N$ tests, because of the controlled nature of the experiment.

\subsection{Turbulence Calculation and Spectral Analysis}

Velocity fluctuations at a single measurement point can be quantified by Reynolds decomposition, where the mean velocity (in this case, only the lateral and vertical wind velocities) is approximated to be zero. It is used to derive the ensemble average of velocity fluctuations to quantify turbulence, which are the standard deviations of fluctuations. The three-dimensional velocity components, longitudinal, lateral and vertical velocity components are denoted as $u, v$ and $w\left(\mathrm{~m} \mathrm{~s}^{-1}\right)$, respectively 
analogous to the $x, y$, and $z$-axes. These velocities were measured using the sonic anemometer at a sampling frequency of $10 \mathrm{~Hz}$. In a similar fashion, standard deviations of fluctuations or turbulence of the three directions are denoted as $\sigma_{u}$, $\sigma_{v}$ and $\sigma_{w}$, respectively. Turbulence can be calculated by the standard deviations of fluctuations $\left(u^{\prime}, v^{\prime}\right.$ and $\left.w^{\prime}\right)$ from the mean velocities $(\bar{U}, \bar{v}$ and $\bar{w})$. Note that mean (ensemble) is represented by the overbar. Equations 1, 2 and 3 calculate the three flow velocity fluctuations:

$$
\begin{array}{ll}
\text { Longitudinal: } & u=\bar{U}+u^{\prime} \\
\text { Lateral: } & v=\bar{v}+v^{\prime} \\
\text { Vertical: } & w=\bar{w}+w^{\prime}
\end{array}
$$

Mean flow speed, $\bar{u}$, for every ensemble averaged (in this case 60 -min averaged block) was calculated by Equation 4:

$$
\bar{u}=\sqrt{\bar{U}^{2}+\bar{v}^{2}}
$$

The turbulences for the three velocity directions have been computed using Equations 5, 6 and 7:

$$
\begin{array}{lll}
\text { Longitudinal: } & \sigma_{u}=\frac{\sqrt{\sum(u-\bar{U})^{2}}}{N-1} \\
\text { Lateral: } & \sigma_{u}=\frac{\sqrt{\sum(v-\bar{v})^{2}}}{N-1} \\
\text { Vertical: } & \sigma_{w}=\frac{\sqrt{\sum\left(w-\bar{w}^{2}\right)}}{N-1}
\end{array}
$$

where $N$ is the number of data points within a 60 -min block-averaged window. Using the EC method, the kinematic momentum flux, $\overline{w^{\prime} u^{\prime}}\left(\mathrm{m}^{2} \mathrm{~s}^{-2}\right)$, can be calculated from $u^{\prime}$ and $w^{\prime}$ determined previously. Each turbulence component also represents the longitudinal, lateral, and vertical vortices intensities and sizes, respectively.

The time series $u, v$ and $w$ data were also analysed using the fast Fourier transform (FFT) algorithm or spectral analysis. The analysis is performed through the Matlab's FFT function to ascertain significant frequencies of the flow velocities due to the motion of the VAWT since each turbulent eddy or vortex carries energy on a frequency scale. The distribution of energy at different frequencies can be revealed from the resulting spectrum. The ordinate of the spectrum is the nondimensional spectral power, $n S_{u, v, w}(n) / \sigma_{u, v, w}{ }^{2}$ denoted simply as $S_{p}$, and where 
$S(n)$ is the spectral power as a function of natural frequency, $n$, and the abscissa is the dimensionless frequency, $f=n L / \bar{u}$, where $L$ is the distance from the flow source. The block average of $60 \mathrm{~min}$ managed to capture a broad range of turbulence frequency scales from $5 \mathrm{~Hz}$ to $0.0005 \mathrm{~Hz}$, which encompassed the rotation speed $(<2 \mathrm{~Hz})$ as well as any slow rotational trend at the order of approximately $33 \mathrm{~min}$ $(0.0005 \mathrm{~Hz})$ rotation cycles of the VAWT.

\subsection{The Energy Balance Model}

An energy balance model is developed for the VAWT made only accessible using direct measurements of kinetic energy and turbulent kinetic energy through the EC method. Its time scale is $60 \mathrm{~min}$, as the averaging window of the EC measurements. Its energy components include kinetic energy (KE), turbulent kinetic energy (TKE), energy loss due to surface drag (D), and mechanical energy absorbed by the VAWT (E). From preliminary analysis, D must be included in the model since it was the largest energy sink. The energy balance can be written as Equation 8:

$$
\sum \mathrm{KE}+\sum \mathrm{TKE}=\mathrm{E}+\mathrm{D}+\varepsilon
$$

For the convenience of calculations, all energy components have the units of per unit mass $\left(\mathrm{kg}^{-1}\right)$ or $\mathrm{m}^{2} \mathrm{~s}^{-2}$. The TKE (TKE $=0.5\left(\sigma_{i}^{2}\right)$ where $i=u$, $v$ or $\left.w\right)$, comprises of the three-component turbulences $\sigma_{u}, \sigma_{v}$ and $\sigma_{w}$ while the $\operatorname{KE}\left(\operatorname{KE}=0.5\left(\bar{u}^{2}\right)\right)$, comprises of mean flow speeds, $\bar{u}$. Conventions used are if the velocity is moving along the stream, it is positive, and if it is moving against the stream, it is negative. $\varepsilon$ or the error term is energy not accounted for by the other mentioned energy components such as the mechanical to electrical energy conversion efficiency of the VAWT, which can also be substantial. From EC measurements, KE and TKE were directly measured while D was calculated from the KE and TKE differences between conditions with the VAWT and without the VAWT. $E$ was estimated from the potential difference (Voltage, V) and current (Ampere, A) measurements of the VAWT through its control panel and the performance specifications disclosed by the manufacturer.

\section{RESULTS AND DISCUSSION}

\subsection{Upwind and Downwind Flow and Turbulence Characteristics of the VAWT}

Through direct turbulence measurements using the EC method, the upwind and downwind flows of a Darrieus-type VAWT are characterised. Before the downwind effects of a VAWT is analysed, an investigation on the upwind effects are needed 
since upwind flow contributes to the general efficiency and performance of a VAWT. The result shows that the VAWT modified the distribution and magnitude of upwind flow velocities by generating a cyclone-shaped flow before flowing into the VAWT even though this could be due to the fans generating the flow. However, this observation has also been reported by numerical modelling studies of a Savonious-type VAWT and an H-shaped VAWT, which do not employ fans to generate the flow in their analysis. ${ }^{27,28}$ Furthermore, this fan configuration has been studied and recommended by Wahab and Chong for the design of an indoor testing facility for wind turbines, which should minimise "localised" structures, such as mentioned cyclone-shaped flows. ${ }^{29}$ From Figure 2(a), $\bar{u}$ increased at only specific locations of the upwind flow swept area: (1) the low leeward side by $10 \%$; and (2) top windward side by 50\% (i.e., rows 3 to 6 in column B and rows 1 to 4 in column $\mathrm{D}$, respectively). Note that this figure and proceeding figures use the same axes scale for ease of comparison. Since flow velocity is inversely proportional to pressure, high-pressure zones were generated for $68 \%$ of the upwind swept area. The leeward (column A) and windward (column E) edges of the VAWT exhibited decreased $\bar{u}$, indicating that flows were being diverted into the VAWT and funneled into the low-pressure zones of the cells mentioned above. Reduced in column $\mathrm{C}$ can be explained by the blocking effect of the VAWT mast. ${ }^{13}$ This pattern suggests that the flow in column B diverged towards the ground, while the flow in column D diverged upwards. Overall, the KE of the upwind flow were similar with and without the VAWT.

A simulation study reported that a bell-shaped velocity deficit would occur in the wake of a HAWT, also exhibiting that the wake is dominated by small to large turbulence scales. ${ }^{30}$ The upwind longitudinal turbulence $\left(\sigma_{u}\right)$ profile is directly related to vortices produced by the wind turbine and its performance. ${ }^{31}$ Figure 2(b) shows the vertical profiles of $\sigma_{u}$ at upwind positions with and without the VAWT. Comparing with Figure 2(a), flow directed upward in column D contributed to increased $\sigma_{u}$. However, $\bar{u}$ increased in the lower rows of column B but did not increase $\sigma_{u}$. In almost all columns except for column $\mathrm{D}$, there was decreased $\sigma_{u}$ above the VAWT. Overall, there were reduced TKE due to the VAWT. In columns A and $\mathrm{B}, \sigma_{u}$ were considerably lowered due to reduced $\bar{u}$ possibly caused by reverse flows from the VAWT and its mast. A study reported that a turbine downwind would affect the performance of the turbine upwind if the two turbines are located close to one another probably due to these reverse flows. ${ }^{32}$ 
(a)

\section{Column A}

Column B

Column C

Column D

Column E
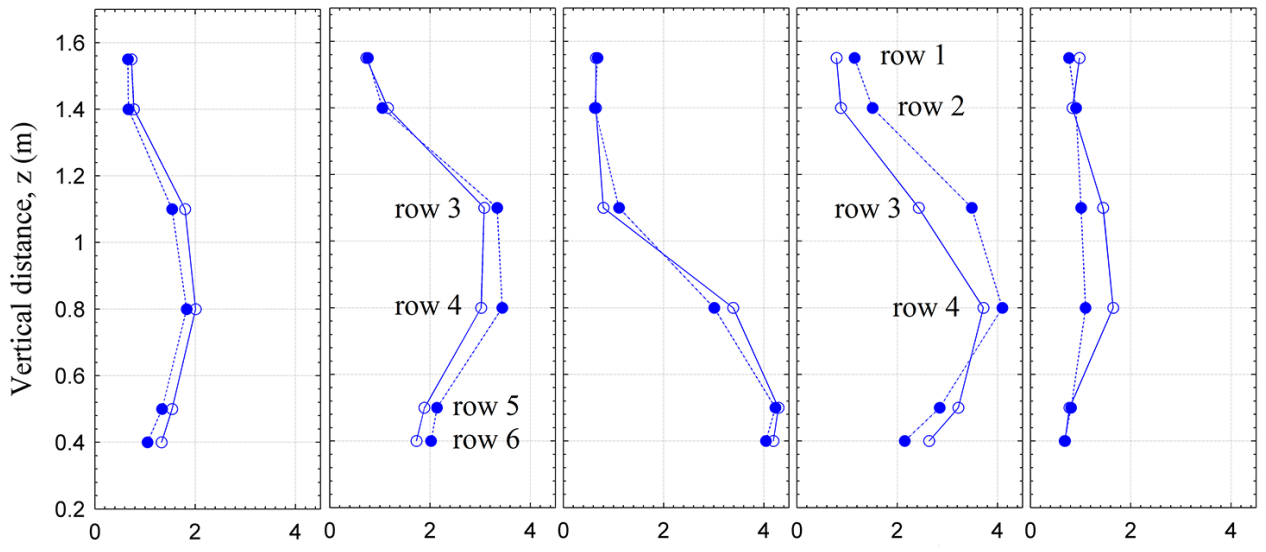

Mean flow velocity, $\bar{u}\left(\mathrm{~m} \mathrm{~s}^{-1}\right)$

(b)

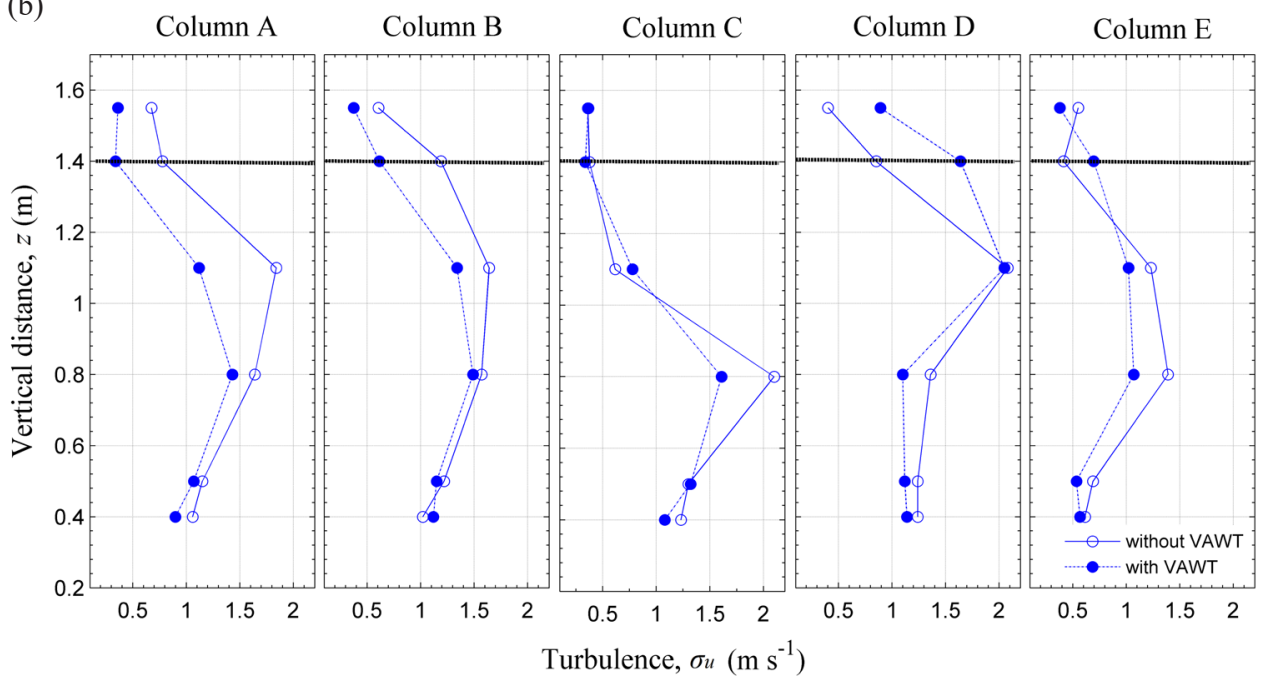

Figure 2: Vertical profiles of (a) mean velocity $(\bar{u})$, and (b) longitudinal turbulence $\left(\sigma_{u}\right)$ at upwind positions without VAWT (represented by blue circle symbols) and with VAWT (represented by filled blue circle symbols). Black dashed line represents the height of VAWT. 
Other studies showed that the flow downwind of a VAWT breaks and travels in three main directions. ${ }^{30,33}$ Our results show that the VAWT only produced two main flow directions; there was also an overall decrease in KE and TKE. Mean $\bar{u}$ substantially reduced to $0.47 \mathrm{~m} \mathrm{~s}^{-1}$ downwind from $3.01 \mathrm{~m} \mathrm{~s}^{-1}$ upwind, which might be due to surface drag, although only $29 \%$ decrease in $\bar{u}$ between with the VAWT (average $1.14 \mathrm{~m} \mathrm{~s}^{-1}$ ) and without the VAWT (average $0.81 \mathrm{~m} \mathrm{~s}^{-1}$ ). This reduction constitutes $<30 \%$ of the Betz's limit, note that maximum Betz's limit is $59 \%$. However, $\bar{u}$ was evenly distributed vertically for all downwind positions with and without the VAWT, as shown in Figure 3(a). Except for column E, the VAWT spread the flow KE vertically and horizontally. In column $\mathrm{E}, \bar{u}$ was the highest of the entire windswept area, which was 1.4 to 2 times greater than other columns and indicates that $80 \%$ of the downwind swept area was high in pressure. Increased flow speed in column E was possibly due to the parallel rotational direction of the VAWT, which channelled the flow to this column. Placing another turbine directly downwind of this column could increase the KE available to the downwind turbine. Dabiri found that by arranging VAWTs in a particular configuration, the collective efficiency of the VAWT array increased due to this channelled flow phenomena. ${ }^{12}$

Figures 3, 4 and 5 show the vertical and lateral profiles of the three turbulence components, $\sigma_{u}, \sigma_{v}$ and $\sigma_{w}$. Figure 3(b) shows a slight increase of $\sigma_{u}$ at the bottom rows as larger secondary vortices formed by the flows reflected upwards by the surface. ${ }^{34}$ Comparing with the downwind flow without the VAWT, Figure 3(b) shows that the VAWT reduced longitudinal TKE aloft and transferred it towards the ground, which produced larger longitudinal vortices. Overall, downwind lateral turbulence $\left(\sigma_{v}\right)$ decreased, especially in the mid-columns B to $\mathrm{C}$ while the VAWT sustained $\sigma_{v}$ for columns A and E. Again, the reflection of turbulence from the surface caused the slight increase in $\sigma_{v}$ in columns D and E, as shown in Figure 4(a). This distribution of lateral turbulence suggests that lateral TKE moved from the centre to the leeward and windward sides. A HAWT wake study using the Detached Eddy Simulation model showed that flow moved vertically behind the turbine although a VAWT might exhibit different flow structures. ${ }^{33}$ Our results show that $\sigma_{w}$ decreased from top to bottom as vertical vortices size reduced in columns $\mathrm{C}$ and $\mathrm{D}$ due to the diverging flow discussed earlier; however, in column $\mathrm{A}$, $\sigma_{w}$ increased while moving towards the surface. This increased vertical turbulence indicates that the VAWT generated larger vertical vortices on the lowest leeward side while producing smaller vertical vortices on the windward side. However, in other swept areas, the lateral profiles show that the VAWT mostly dampened $\sigma v$ and $\sigma_{w}$ from columns $\mathrm{B}$ to $\mathrm{D}$, suggesting that it reduced the vortices sizes when approaching the ground. These results are corroborated by other experimental and numerical studies cited above. 
(a)

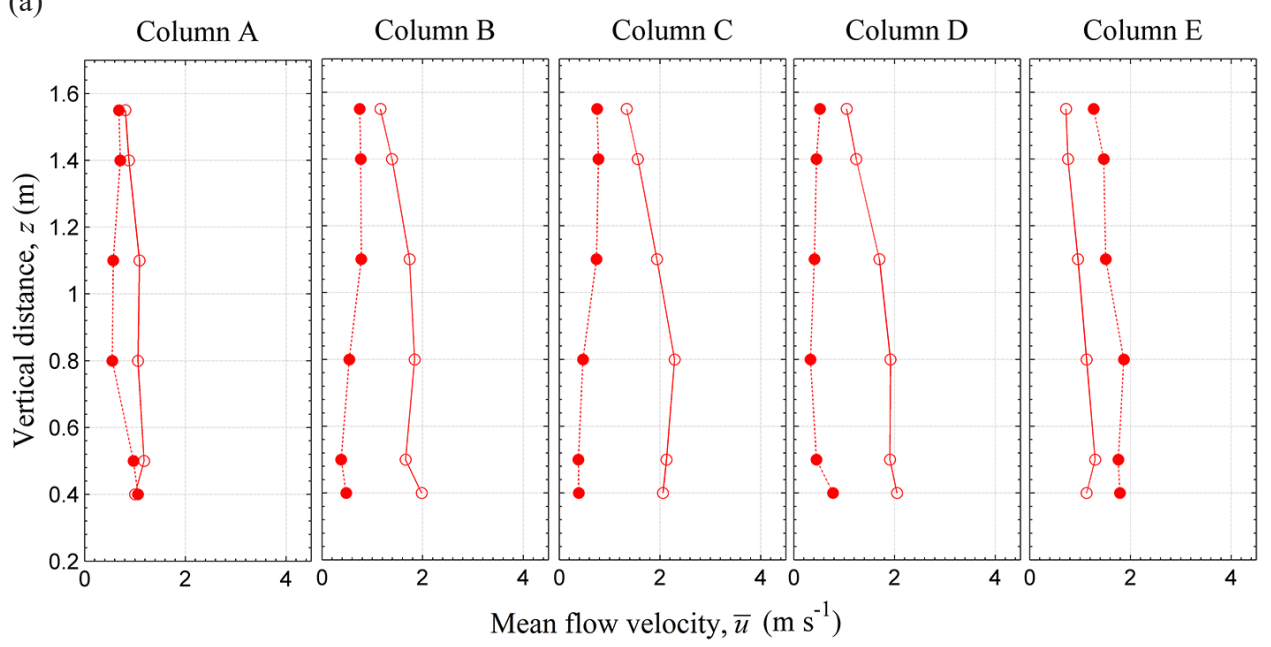

(b)

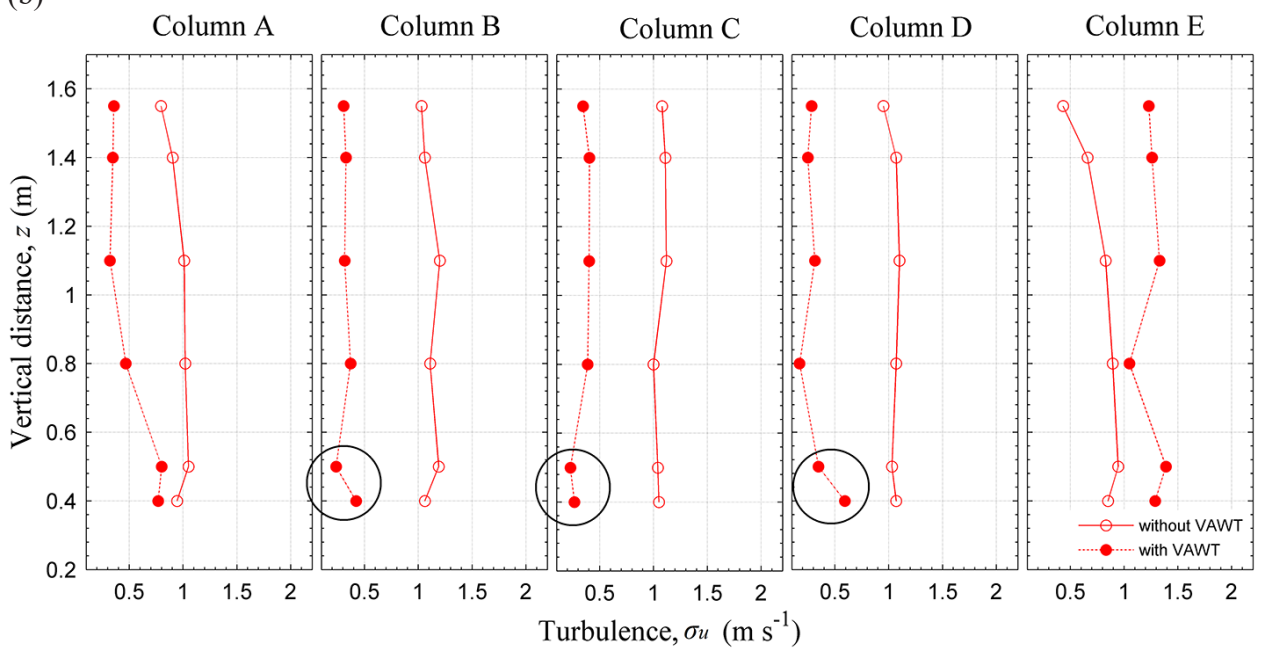

Figure 3: Vertical profiles of (a) mean velocity $(\bar{u})$, and (b) longitudinal turbulence $\left(\sigma_{u}\right)$ at downwind positions, from bottom to top for columns A to E. Red circle symbols represent downwind positions without VAWT while filled red circle symbols represent downwind position with VAWT. 
(a)

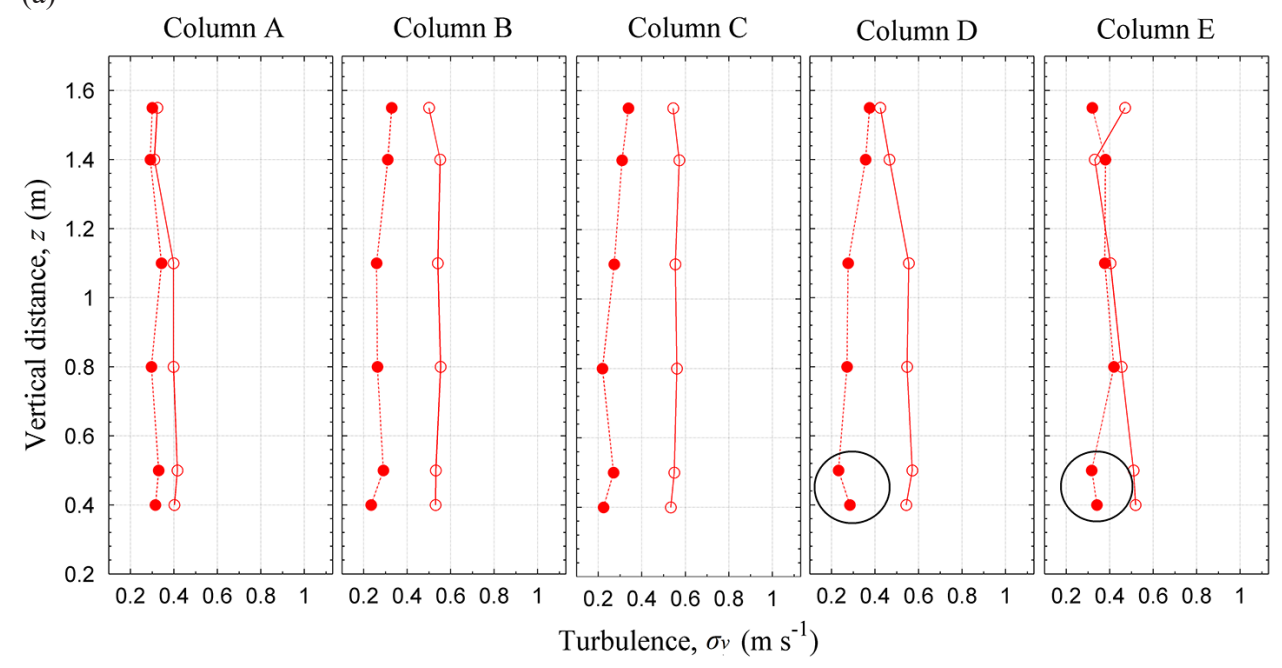

(b)

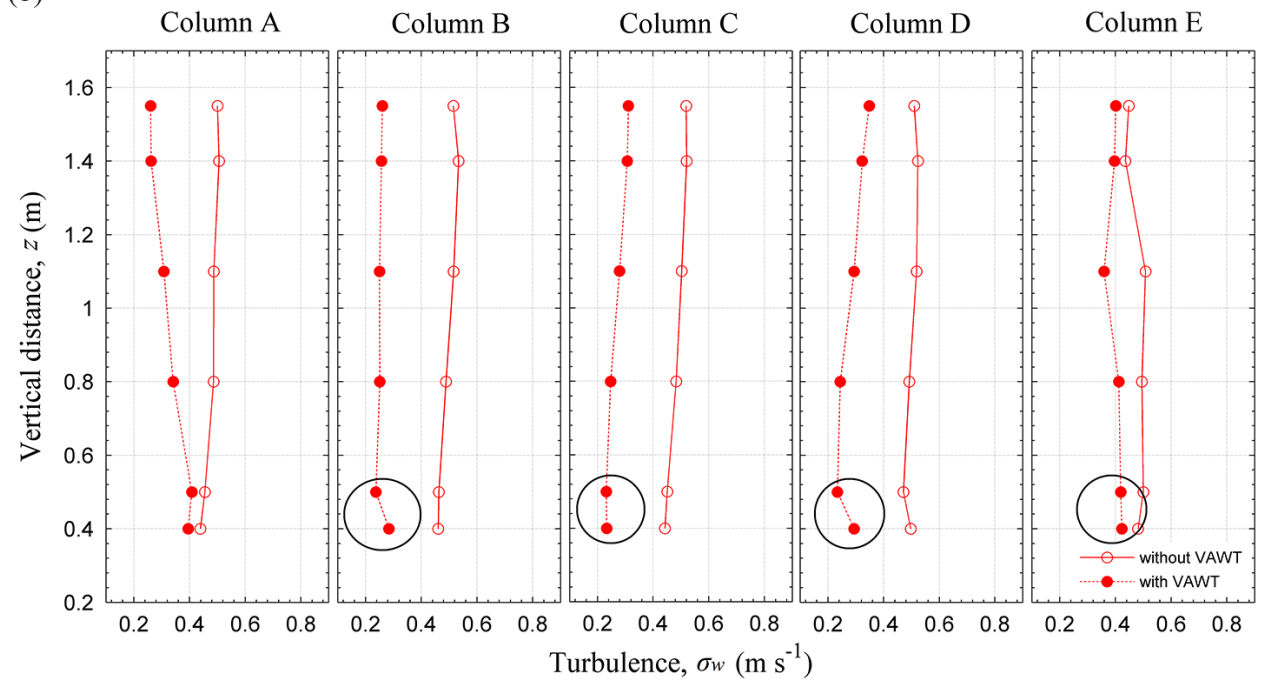

Figure 4: Vertical profiles of (a) lateral, and (b) vertical turbulence $\left(\sigma_{v}\right.$ and $\left.\sigma_{w}\right)$ at downwind positions, from bottom to top for each column (A to E) without the VAWT (represented by red circle symbols) and with the VAWT (represented by filled red circle symbols). 
(a)

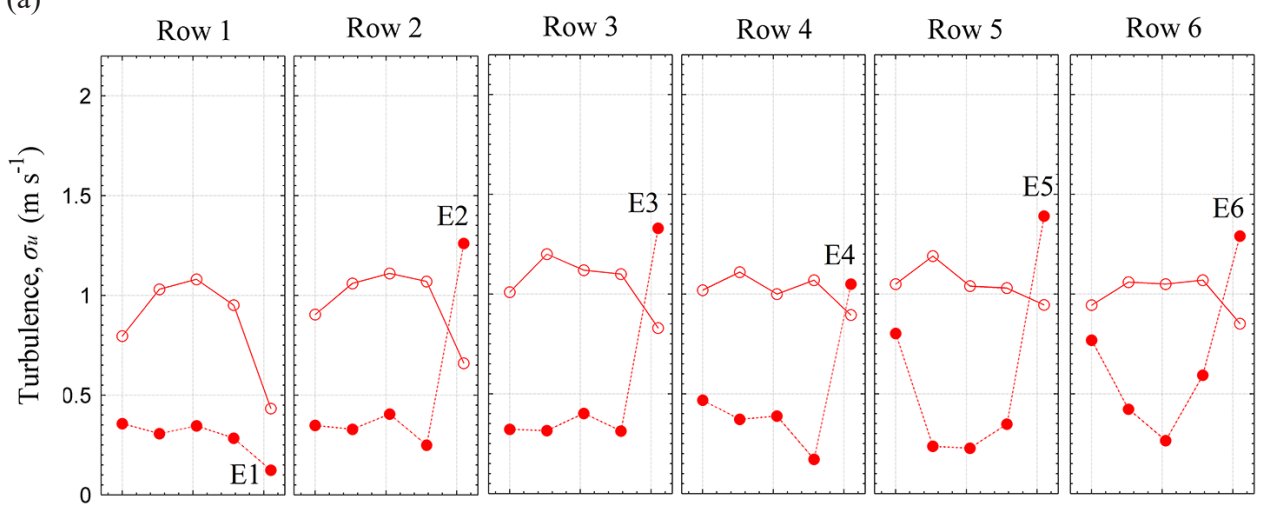

(b)
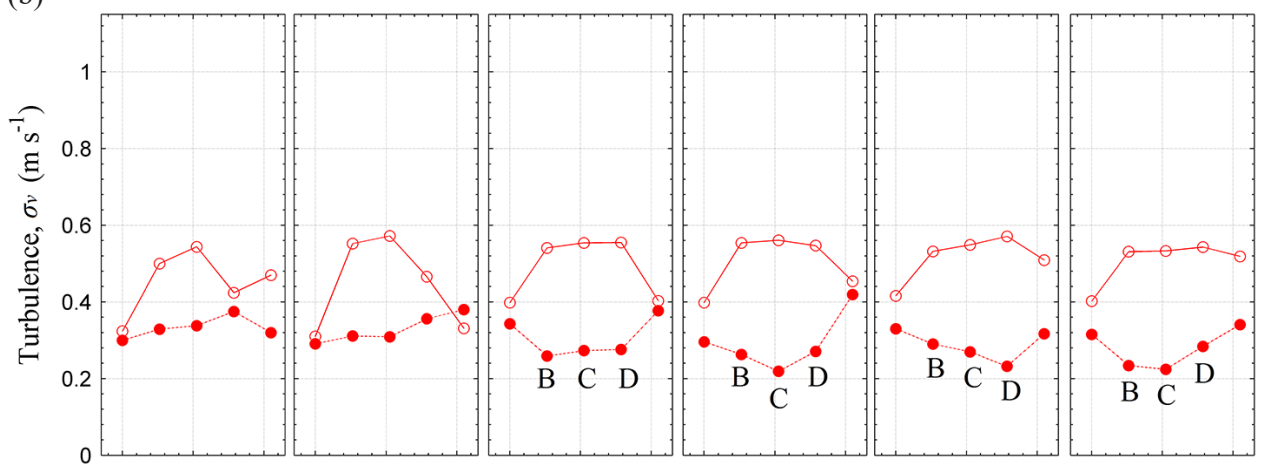

(b)
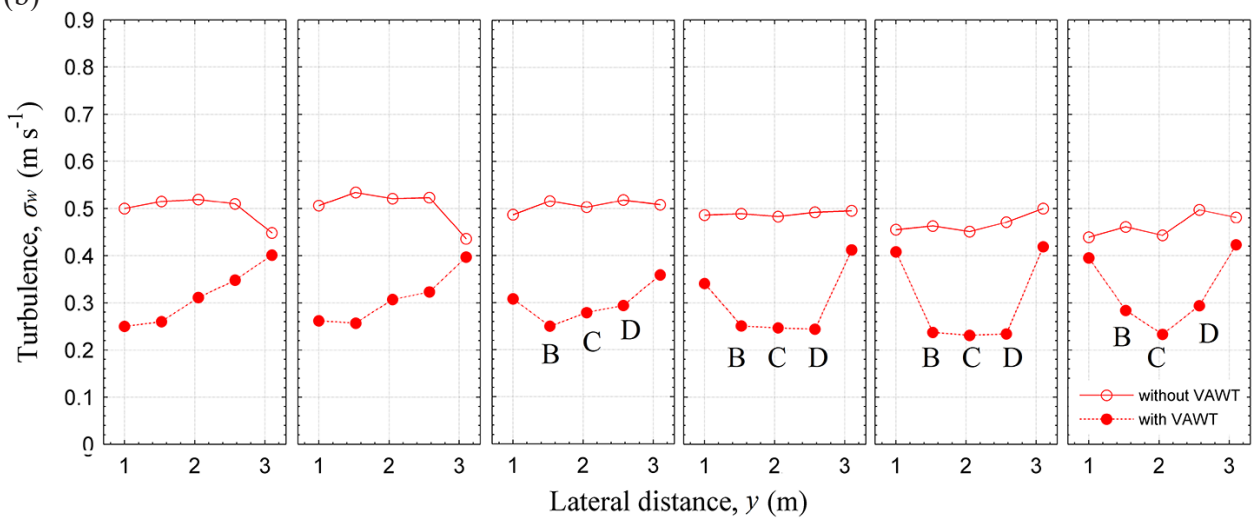

Figure 5: Lateral profiles of (a) longitudinal, (b) lateral, and (c) vertical turbulence $\left(\sigma_{u}\right.$, $\sigma_{v}$ and $\sigma_{w}$ ) at downwind positions, from left to right for each column (A to E) and for each row (1 to 6) without the VAWT (represented by red circle symbols) and with the VAWT (represented by filled red circle symbols). 


\subsection{Energy Balance Analysis}

Energy balance, grounded by the conservation of mass, momentum and energy, has important applications in numerical simulations. The energy balance of upwind flow (the plane perpendicular to the streamwise flow with and without the VAWT) for KE and TKE showed that total energy (KE + TKE) was removed from the flow when the VAWT was downwind. The energy balance with the unit of energy is per unit mass $\left(\mathrm{J} \mathrm{kg}^{-1}\right)$ can be written as Equation 9:

$$
\sum_{i=1}^{c} 0.5\left(\bar{u}_{i}^{2}+\sigma_{u}^{2}+\sigma_{v}^{2}+\sigma_{w}^{2}\right)_{1}-\sum_{i=1}^{c} 0.5\left(\bar{u}_{i}^{2}+\sigma_{u}^{2}+\sigma_{v}^{2}+\sigma_{w}^{2}\right)_{2}=0
$$

where $c$ is the cell number, $i$ is the $i$-th cell number, and subscripts 1 and 2 denote without VAWT and with VAWT, respectively. The results show that total KE increased by $3 \%$ (KE without the VAWT was $134.57 \mathrm{~J} \mathrm{~kg}^{-1}$ while KE with the VAWT was $138.30 \mathrm{~J} \mathrm{~kg}^{-1}$ ). Total TKE decreased by $15 \%$ (TKE without the VAWT was $63.83 \mathrm{~J} \mathrm{~kg}^{-1}$ while TKE with the VAWT was $54.88 \mathrm{~J} \mathrm{~kg}^{-1}$ ), which suggests that the VAWT increased flow speed and reduced turbulence resulting in less overall energy available in the incoming flow. Reduction in TKE also implies that vortices sizes and energies decreased before flowing into the VAWT.

The energy balance of the VAWT can be written as Equation 10:

$$
\sum_{i=1}^{c} \mathrm{TKE}_{\text {up }}+\sum_{i=1}^{c} \mathrm{KE}_{\text {up }}=\sum_{i=1}^{c} \mathrm{TKE}_{\text {down }}+\sum_{i=1}^{c} \mathrm{KE}_{\text {down }}+\mathrm{D}+\mathrm{E}+\varepsilon
$$

where the subscripts "up" and "down" denote upwind and downwind, respectively. When analysing the energy balance with the VAWT downwind, it shows that $67 \%$ of the incoming KE was lost from the flow $\left(\mathrm{KE}_{\text {down }}=22.90 \mathrm{~J} \mathrm{~kg}^{-1}\right.$ and $\mathrm{KE}_{\text {up }}=69.15$ $\left.\mathrm{J} \mathrm{kg}^{-1}\right)$. The VAWT also reduced the incoming flow TKE by $70 \%\left(\mathrm{TKE}_{\text {down }}=8.10\right.$ $\mathrm{J} \mathrm{kg}^{-1}$ and $\mathrm{TKE}_{\text {up }}=27.44 \mathrm{~J} \mathrm{~kg}^{-1}$ ). This reduction indicates that the VAWT lessened both KE and TKE energies equally; total KE and TKE was $96.59 \mathrm{~J} \mathrm{~kg}^{-1}$. This calculation also considers the energy loss due to surface drag $\left(\mathrm{KE}_{\text {drag }}+\mathrm{TKE}_{\text {drag }}\right)$, $D$, which constituted about $44 \%\left(D=43.04 \mathrm{~J} \mathrm{~kg}^{-1}\right)$ of the total energy within the incoming flow. Therefore, the available net energy to the VAWT was $31 \mathrm{~J} \mathrm{~kg}^{-1}$.

From the power curve reported by the VAWT manufacturer, at the approximate VAWT RPM range measured of 100-105 RPM, the power generated by the VAWT was $15 \mathrm{~W}$. Note that the power curve for the VAWT has been published in H'ng et al. ${ }^{19}$ This was also confirmed by the potential difference $(=7.5 \mathrm{~V})$ and current measurements (=2 A) observed. The $15 \mathrm{~W}$ corresponds with $3.16 \mathrm{~J} \mathrm{~kg}^{-1}$; swept area of $1.3 \mathrm{~m} \times 1.5 \mathrm{~m}$ (width $\times$ height) at an average speed of $1.8 \mathrm{~m} \mathrm{~s}^{-1}$ (for all cells) and air density of $1.184 \mathrm{~kg} \mathrm{~m}^{-3}$. The mass flow rate was calculated to be $4.16 \mathrm{~kg} \mathrm{~s}^{-1}$. 
These numbers result in the VAWT having a power generation efficiency of approximately $C_{p}=12 \%$, which is the average efficiency rating reported by many VAWT manufacturers and studies in this flow speed range. ${ }^{35}$ Without giving TKE due consideration, the efficiency was overestimated to $16 \%$, which indicates the significance of turbulence in the VAWT energy budget. Furthermore, the optimal operation of the VAWT depends on turbulence, notably improved self-starting performance. ${ }^{36}$ Finally, the partitioning of energy downwind of the VAWT is $12 \%$ for the energy absorbed by the VAWT, $42 \%$ for the KE, $31 \%$ for the TKE, and $15 \%$ for the mechanical energy to electrical energy conversion loss due to the VAWT. This partitioning indicates that more work on the design of the VAWT are needed to increase the energy conversion efficiency of the VAWT.

\subsection{Characteristics and Role of the Vertical Momentum Flux $\overline{w^{\prime} u^{\prime}}$ in the Energy Balance}

Studies on an array of VAWTs found that there could be increased energy available to the VAWT through the planform transfer of momentum energy. ${ }^{13,37}$ Here, the magnitude and trend of the vertical momentum flux transfer for a single VAWT are investigated. Vertical profile of the vertical momentum flux, $\overline{w^{\prime} u^{\prime}}$, is shown in Figure 6, and it only considered the downwind positions here since the trends, for both upwind and downwind positions, were similar.

In general, when the flow dispersed downwind, $\overline{w^{\prime} u^{\prime}}$ transferred from top to bottom due to surface drag without the VAWT, indicating that significant momentum transfer to the surface occurs regardless of the VAWT in all columns (Figure 6). Once the VAWT was within the flow, a substantial decline of $\overline{w^{\prime} u^{\prime}}$ appeared but only in column E while $\overline{w^{\prime} u^{\prime}}$ was approximately zero from top to bottom of columns A to D. This suggests that no momentum transfer occurred in much of the swept area of the VAWT. The highest momentum flux value took place in column E above the VAWT, where $\overline{w^{\prime} u^{\prime}}$ was forced downward by the windward edge of the VAWT. This downward movement is similar to the results of a HAWT study, where the HAWT generated turbulence mixing and momentum transfer in the upper wake of the turbine. ${ }^{38}$ Our results also agreed well with the study by Dörenkämper et al. in which the vertical kinematic flux-closely linked to $\overline{w^{\prime} u^{\prime}}$ -was elevated in the upper region of the turbine and suppressed at the bottom region due to the wake effect. ${ }^{39} \mathrm{~A}$ study by $\mathrm{Wu}$ and Porte-Agel also corroborate this result in which the highest momentum transfer occurred in the upper right region in the wake of VAWT. ${ }^{40}$ 
The overall contribution of $\mathrm{TKE}_{\text {momentum }}=0.5 \overline{w^{\prime} u^{\prime}}$ to the energy budget was minimal with only a total energy of $0.19 \mathrm{~J} \mathrm{~kg}^{-1}$ available to the VAWT or $<1 \%$ of the energy available calculated in Section 3.2. However, the location of where the VAWT absorbed the energy was in a specific area in which the VAWT directed momentum transfer to the windward edge of the VAWT (i.e., approximately $2 / 3$ of the height of the VAWT from the surface and in its windward side; see column E of Figure 6). The surface absorbed most of the energy through the vertical transfer of momentum or drag as discussed above $\left(=-1.39 \mathrm{~J} \mathrm{~kg}^{-1}\right)$. The input energy was $-1.25 \mathrm{~J} \mathrm{~kg}^{-1}$. Thus, the surface drag increased the amount of momentum transfer to the surface and therefore could be beneficial to the VAWT by increasing the overall energy available. These results show that momentum flux energy that could be absorbed by the VAWT would be minimal and insignificant compared to overall KE and TKE, however its effects on larger arrays of VAWTs require further study.

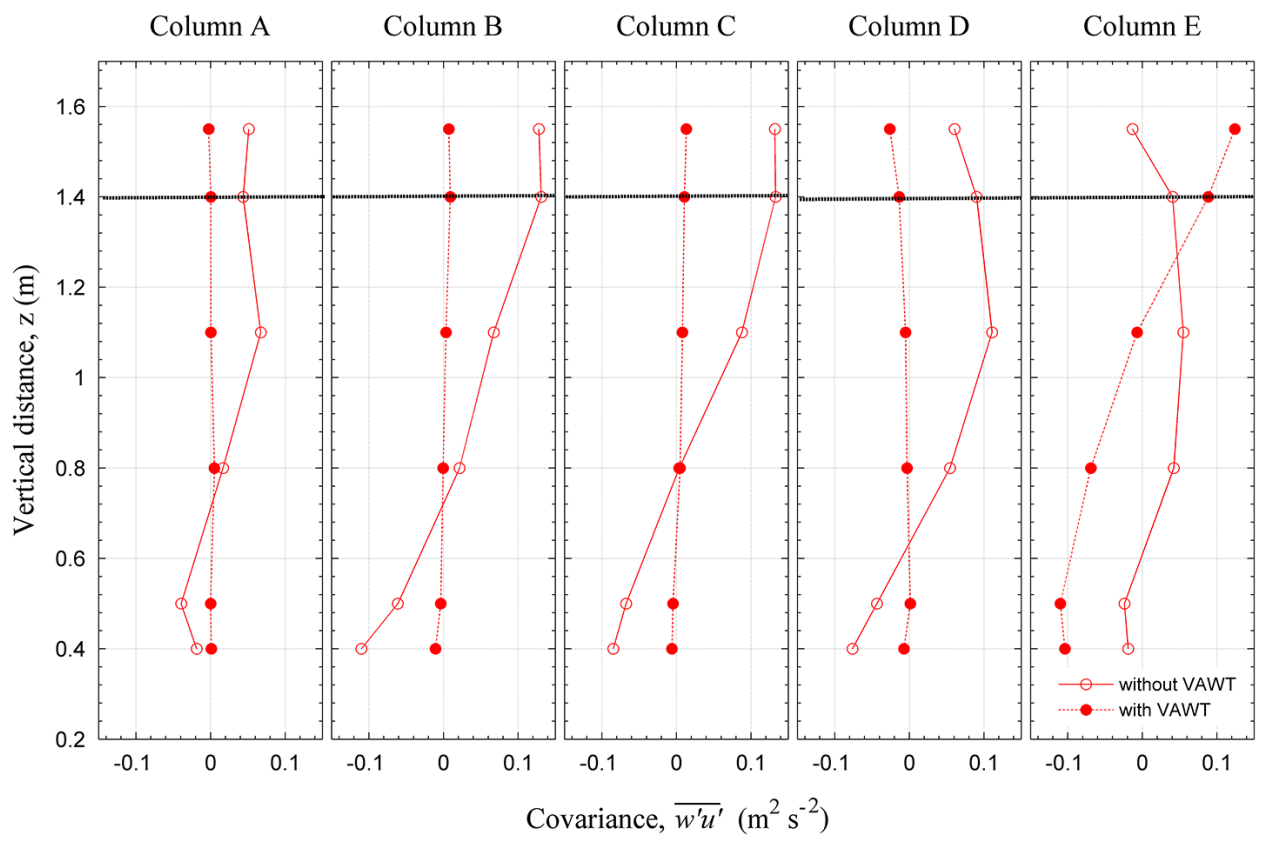

Figure 6: Vertical profiles of vertical momentum transfer, $\overline{w^{\prime} u^{\prime}}$ from bottom to top for each column (A to E) at downwind positions, without the VAWT (represented by red circle symbols) and with the VAWT (represented by filled red circle symbols). Black dashed line represents the height of VAWT. 


\subsection{Spectral Analysis of the Downwind Flow of the VAWT}

To fully understand the turbulent processes and mechanism of the VAWT, the spectra of $\overline{w^{\prime} u^{\prime}}$ at different frequencies using FFT is referred. The covariance $\overline{w^{\prime} u^{\prime}}$ can act as a representative of the other velocity components or covariance spectra since their trends were similar. From Figures 7 and 8, the abscissa is the natural frequency, $n(\mathrm{~Hz})$, and the ordinate is the non-dimensional spectra power, $S_{p}$. The vortices, at different frequencies, carry different energy levels, which reveals its power for each frequency (or wavelength) scale. Hence, the sizes of the vortices from $S_{p}$ can be inferred. By referring previous spectral analysis studies, researchers typically calculated the spectra for the entire windswept area of the VAWT..$^{12,13}$ However, only the spectra for row 2 and column E (windward edge) are presented here, as this row experienced the highest momentum flux compared to other rows entering the planform area of the VAWT while column E was where the most momentum flux transfer occurred (Figure 6).

Figure 7 shows the lateral profile of spectra power for $\overline{w^{\prime} u^{\prime}}$ in row 2, while Figure 8 shows the vertical profile of spectra power for $\overline{w^{\prime} u^{\prime}}$ in column E (rows 2 to 6). Although not shown here, the spectra for $u, v$ and $w$ also exhibited similar structures. Due to the nature of the flow generated by the standing fans, the highest energy (of approximately $1 \mathrm{~Hz}$ ) was stored in the small vortices and dissipated to lower and upper frequencies as compared to natural wind (of approximately $0.1 \mathrm{~Hz}$ ). This dissipation was the same for with and without the VAWT. The difference between them is the vortices within the frequency range of $1 \mathrm{~Hz}$ to $5 \mathrm{~Hz}$, where the spectra with the VAWT exhibited higher $S_{p}$ than without the VAWT, particularly for columns B2 to E2 and E2 to E6. Thus, smaller but faster momentum flux vortices were created by the VAWT due to the rotating rotors. However, energy was extracted by the VAWT at frequency $0.1 \mathrm{~Hz}$, evident from the reduced $S_{p}$ (Figure 7). Figure 8 illustrates the vertical profile of $\overline{w^{\prime} u^{\prime}}$ distribution in column E, revealing the threshold where the energy began to be included in the flow and extracted from the flow. The VAWT rotated in a counter clockwise fashion with some streams directed upwards at the windward edge column (column E). The flow moving upwards created small vortices $(>1 \mathrm{~Hz})$ detected at positions E2 and E4. In contrast, the VAWT removed energy from the flow at $2 / 3$ of the height of the VAWT from the surface (E5). 

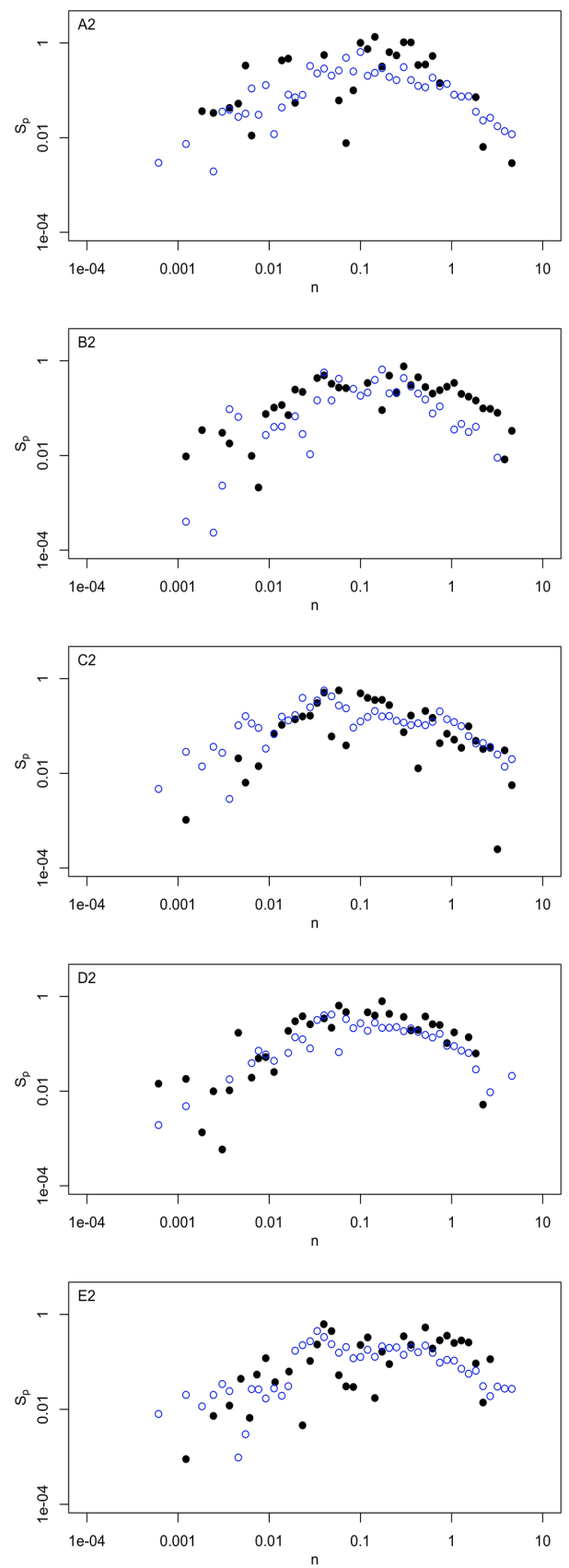

Figure 7: Lateral profiles of the spectra power distribution of $\overline{w^{\prime} u^{\prime}}$ for each column (A to E) for row 2 at downwind positions, without the VAWT (denoted as unfilled blue circles) and with the VAWT (denoted as filled black circles). $S p$ is spectral power (dimensionless) and $n$ is natural frequency $(\mathrm{Hz})$. 

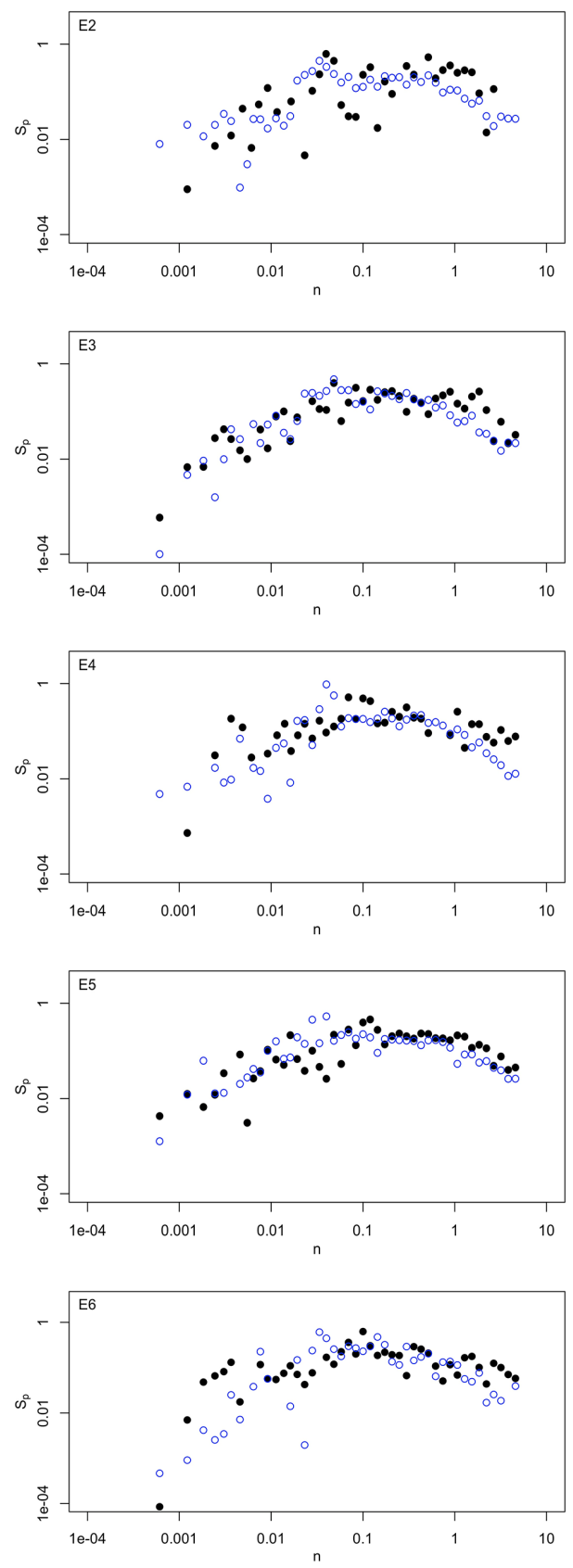

Figure 8: Vertical profiles of the spectra power distribution of $\overline{w^{\prime} u^{\prime}}$ for each row (2 to 6) for column E at downwind positions, without the VAWT (denoted as unfilled blue circles) and with the VAWT (denoted as filled black circles). Sp is spectral power (dimensionless) and $n$ is natural frequency $(\mathrm{Hz})$. 


\section{CONCLUSION}

Lateral and vertical profiles of turbulence and flow characteristics provided an in-depth understanding of the flow upwind and downwind of the windswept area of the VAWT. Through energy balance analysis of the upwind streamwise flow, the result shows that there was an overall increase in KE but an overall decrease in TKE. Downwind of the VAWT, flow speed and turbulence reduced due to flow dispersion and surface drag. The VAWT contributed to high $\bar{u}$ in the windward edge of the VAWT, which was approximately 1.4 to 2 times greater than other windswept areas. There was an increase of flow velocity and turbulence at the bottom downwind region of the VAWT. Energy balance analysis showed a significant drop in KE before and after the VAWT (72\% to $42 \%$ ) but a slight rise in TKE (28\% to $31 \%$ ). Effects of momentum flux on the overall energy budget were minimal (i.e., $<1 \%$ of available energy) although most of the energy transfer occurred at the windward edge. Spectral analysis shows that the VAWT created smaller but faster momentum flux vortices at the frequency $>1 \mathrm{~Hz}$ due to the rotating VAWT rotors. This analysis also shows that the VAWT extracted wind energy at the frequency of $0.1 \mathrm{~Hz}$. The spectra reveal that below $2 / 3$ of the height of the VAWT, momentum flux energy transferred out of the flow, while above this height, it moved into the flow. This data and results have important applications to assist in accurately modelling complex flows around VAWTs. However, more work is needed to understand VAWT flows as different types of VAWTs will exhibit different flow characteristics.

\section{ACKNOWLEDGEMENTS}

The authors express their gratitude to the Malaysian Ministry of Education and Universiti Sains Malaysia (USM) for awarding the Fundamental Research Grant Scheme (FRGS) to conduct this research (grant no. 203/PTEKIND/6711329) and the USM short-term grant (grant no. 304/PTEKIND/6312099). Appreciation also goes to Universiti Teknologi Malaysia for the Ainuddin Wahid scholarship, which provides financial assistance to author Y.M. H'ng from the Malaysia-Japan International Institute of Technology.

\section{REFERENCES}

1. Balduzzi, F. et al. (2012). Feasibility analysis of a Darrieus vertical-axis wind turbine installation in the rooftop of a building. Appl. Energy, 97, 921-929, https://doi.org/10.1016/j.apenergy.2011.12.008. 
2. Mertens, S. (2002). Wind energy in urban areas: Concentrator effects for wind turbines close to buildings. Refocus, 3(2), 22-24, https://doi.org/10.1016/S14710846(02)80023-3.

3. Didane, D. H. et al. (2018). Performance evaluation of a novel vertical axis wind turbine with coaxial contra-rotating concept. Renew. Energ., 115, 353-361, https://doi.org/10.1016/j.renene.2017.08.070.

4. Aravind, C. V. et al. (2012). A novel magnetic levitation assisted vertical axis wind turbine: Design procedure and analysis. Paper presented at the 2012 IEEE 8th International Colloquium on Signal Processing and its Applications, 23-25 March, Melaka, Malaysia.

5. Aravind, C. et al. (2014). Design analysis of MAGLEV-VAWT with modified magnetic circuit generator. Paper presented at the IEEE 2nd International Conference on Electrical Energy Systems (ICEES), 7-9 January, Chennai, India.

6. Khan, S. et al. (2013). Performance analysis of 20 pole $1.5 \mathrm{~kW}$ three phase permanent magnet synchronous generator for low speed vertical axis wind turbine. Energy Power Eng., 5(4B), 423-428, https://doi.org/10.4236/epe.2013.54B082.

7. Teow, W. W. \& Aravind, C. V. (2018). Magnetic geared radial axis vertical wind turbine for low velocity regimes. MATEC Web Conf., 152, 03007, https://doi. org/10.1051/matecconf/201815203007.

8. Khan, M. S. A. et al. (2016). Feasibility study of a novel 6V supercapacitator based energy harvesting circuit integrated with vertical axis wind turbine for low wind areas. Int. J. Renew. Energy Res., 6(3), 1167-1177.

9. Tabrizi, A. B. et al. (2015). Rooftop wind monitoring campaigns for small wind turbine applications: Effect of sampling rate and averaging period. Renew. Energy, 77, 320-330, https://doi.org/10.1016/j.renene.2014.12.037.

10. Islam, M. R., Saidur, R. \& Rahim, N. A. (2011). Assessment of wind energy potentiality at Kudat and Labuan, Malaysia using Weibull distribution function. Energy, 36(2), 985-992, https://doi.org/10.1016/j.energy.2010.12.011

11. Nor, K. M., Shaaban, M. \& Rahman, H. A. (2014). Feasibility assessment of wind energy resources in Malaysia based on NWP models. Renew. Energy, 62(2014), 147-154, https://doi.org/10.1016/j.renene.2013.07.001

12. Dabiri, J. O. (2011). Potential order-of-magnitude enhancement of wind farm power density via counter-rotating vertical-axis wind turbine arrays. J. Renew. Sustain. Energy, 3(4), 1-12, https://doi.org/10.1063/1.3608170.

13. Kinzel, M., Mulligan, Q. \& Dabiri, J. O. (2013). Energy exchange in an array of vertical axis wind turbines. J. Turbul., 14(6), 38-39, https://doi.org/10.1080/1468 5248.2013.825725.

14. Anderson, D. C. et al. (2008). Rooftop wind resource assessment using a ThreeDimension Ultrasonic Anemometer. Paper presented at the 7th World Wind Energy Conference (WWEC2008), Kingston, Canada, 24-26 June.

15. Vermeer, L. J., Sorensen, J. N. \& Crespo, A. (2003). Wind turbine wake aerodynamics. Prog. Aerosp. Sci., 39(6-7), 467-510, https://doi.org/10.1016/ S0376-0421(03)00078-2.

16. Roth, M. (2000). Review of atmospheric turbulence over cities. Quart. J. Roy. Meteor. Soc., 126(564), 941-990, https://doi.org/10.1002/qj.49712656409. 
17. Tabrizi, A. B. et al. (2015). Extent to which international wind turbine design standard, IEC61400-2 is valid for a rooftop wind installation. J. Wind. Eng. Ind. Aerod., 139, 50-61, https://doi.org/10.1016/j.jweia.2015.01.006.

18. Wharton, S. \& Lundquist, J. K. (2012). Atmospheric stability affects wind turbine power collection. Environ. Res. Lett., 7(1), 014005, https://doi.org/10.1088/17489326/7/1/014005.

19. H'ng, Y. et al. (2014). Pilot study on indoor flows and turbulence statistics of a vertical axis wind turbine. Mech. Eng. Res., 4(1), 63-78, https://doi.org/10.5539/ mer.v4n1p63.

20. Yang, Z. F., Sarkar, P. \& Hu, H. (2012). Visualization of the tip vortices in a wind turbine wake. J. Vis.-Jap., 15(1), 39-44, https://doi.org/10.1007/s12650-0110112-z.

21. Wahab, A. A. \& Tong, C. W. (1999). Utilizing the energy from induced wind produce by highway vehicle motions. Paper presented at the World Renewable Energy Congress 99, Kuala Lumpur, Malaysia, 8-11 June.

22. Ragheb, M. \& Ragheb, A. M. (2011). Wind turbines theory: The Betz Equation and optimal rotor tip speed ratio. In Carriveau, R. (Ed.). Fundamental and advanced topics in wind power. Rijeka: InTech, 19.

23. Vickers, D. \& Mahrt, L. (1997). Quality control and flux sampling problems for tower and aircraft data. J. Atmos. Ocean. Technol., 14(3), 512-526, https://doi. org/10.1175/1520-0426(1997)014<0512:QCAFSP >2.0.CO;2.

24. Yusup, Y. \& Anis, S. I. (2016). Similarity theory and nocturnal locally scaled turbulence variances in the tropical urban roughness sublayer. Atmos. Pollut. Res., 7(3), 454-468, https://doi.org/10.1016/j.apr.2015.11.002.

25. Yusup, Y. \& Lim, J. F. (2014). Turbulence variances in the convective urban roughness sublayer: An application of similarity theory using local scales. Meteorol. Appl., 21(2), 149-160, https://doi.org/10.1002/met.1316.

26. Stull, R. B. (1988). An introduction to boundary layer meteorology. Boston: Kluwer Academic Publishers.

27. D'Alessandro, V. et al. (2010). Unsteady aerodynamics of a Savonius wind rotor: A new computational approach for the simulation of energy performance. Energy, 35(8), 3349-3363, https://doi.org/10.1016/j.energy.2010.04.021.

28. Tescione, G., Simão Ferreira, C. J. \& van Bussel, G. J. W. (2016). Analysis of a free vortex wake model for the study of the rotor and near wake flow of a vertical axis wind turbine. Renew. Energy, 87(1), 552-563, https://doi.org/10.1016/j. renene.2015.10.002.

29. Wahab, A. A. \& Chong, W. T. (2003). Development of an indoor testing facility for low wind speed wind turbine research activities. Paper presented at the Proceedings of the 2nd Regional Conference on Energy Technology Towards a Clean Environment, Phuket, Thailand, 12-14 February.

30. Troldborg, N., Sorensen, J. N. \& Mikkelsen, R. (2007). Actuator line simulation of wake of wind turbine operating in turbulent inflow. J. Phys. Conf. Ser., 75(1), 12063-12063, https://doi.org/10.1088/1742-6596/75/1/012063. 
31. Hansen, K. S. et al. (2012). The impact of turbulence intensity and atmospheric stability on power deficits due to wind turbine wakes at Horns Rev wind farm. Wind Energy, 15(1), 183-196, https://doi.org/10.1002/we.512.

32. Breton, S. P. et al. (2014). Comparative CFD study of the effect of the presence of downstream turbines on upstream ones using a rotational speed control system. $J$. Phys. Conf. Ser., 555(1), https://doi.org/10.1088/1742-6596/555/1/012014.

33. Hasager, C. B. et al. (2013). Wind farm wake: The Horns Rev photo case. Energies, 6(2), 696-716, https://doi.org/10.3390/en6020696.

34. Hunt, J. C. R. \& Morrison, J. F. (2000). Eddy structure in turbulent boundary layers. Eur. J. Mech. B-Fluid., 19(5), 673-694, https://doi.org/10.1016/S09977546(00)00129-1.

35. Tummala, A. et al. (2016). A review on small scale wind turbines. Renew. Sust. Energ. Rev., 56, 1351-1371, https:// doi.org/10.1016/j.rser.2015.12.027.

36. Peng, H. Y. \& Lam, H. F. (2016). Turbulence effects on the wake characteristics and aerodynamic performance of a straight-bladed vertical axis wind turbine by wind tunnel tests and large eddy simulations. Energy, 109, 557-568, https://doi. org/10.1016/j.energy.2016.04.100

37. Kinzel, M., Araya, D. B. \& Dabiri, J. O. (2015). Turbulence in vertical axis wind turbine canopies. Phys. Fluids, 27(11), 115102, https://doi.org/10.1063/1.4935111.

38. Jha, P. et al. (2015). Unraveling the mysteries of turbulence transport in a wind farm. Energies, 8(7), 6468, https://doi.org/10.3390/en8076468.

39. Dörenkämper, M. et al. (2015). The impact of stable atmospheric boundary layers on wind-turbine wakes within offshore wind farms. J. Wind. Eng. Ind. Aerod., 144, 146-153, https://doi.org/10.1016/j.jweia.2014.12.011.

40. Wu, Y. T. \& Porte-Agel, F. (2012). Atmospheric turbulence effects on windturbine wakes: an LES study. Energies, 5(12), 5340-5362, https://doi.org/10.3390/ en5125340. 